\title{
Direct Growth of Carbon Nanotubes on Metal Supports by Chemical Vapor Deposition
}

\author{
Naiqin Zhao ${ }^{1}$ and Jianli Kang ${ }^{2}$ \\ ${ }^{1}$ School of Materials Science and Engineering, Tianjin University, China \\ Tianjin Key Laboratory of Composite and Functional Materials, Tianjin, \\ ${ }^{2}$ School of Mechanical Engineering, Tianjin Polytechnic University, \\ WPI Advanced Institute for Materials Research, Tohoku University, \\ ${ }^{1}$ China \\ ${ }^{2}$ Japan
}

\section{Introduction}

Since their discovery (Iijima, 1991), carbon nanotubes (CNTs) have been attracted much attention due to their excellent mechanical, physical and chemical properties. In the past thirty years, thousands of articles have been published to discuss their growth, properties, and applications. For the CNT growth, there are three main methods: arc discharge, laser ablation and chemical vapour deposition (CVD). Compared with the first two methods, CVD was regarded as the most promising one for industrial application with low cost, although it usually introduces more defects in CNTs during the growth process. Furthermore, CVD is the preferred choice to grow patterned CNTs on substrates for nanoelectronic applications. Typically, nanotubes are grown by CVD on metal catalyst particles or islands that are deposited on top of semiconducting or insulating materials, such as alumina, silicon and silicon oxide. These non-conducting substrates assist in the formation of small islands or nanoparticles of metal catalyst on their surfaces, which is necessary for the CNT growth. However, for many applications, such as displays, cell electrodes, gigascale interconnects, high electrical and thermal conductivities are required, usually needing a conductive substrate to connect with CNTs. Furthermore, minimization of the contact resistance between metal substrate and CNTs is also a major challenge in nanoelectronics. Apart from geometrical factors, contact resistance depends mostly on alignment of Fermi energy levels of CNT and substrate. Since multi-walled CNTs are predominantly metallic (Single-walled CNTs can be adjusted to be metallic by controlling their structure), a metallic substrate to connect with CNTs is expected to have least contact resistance. In order to assemble the CNTs on metal substrate with fine patterned architectures, the obvious and effective way would be to grow CNTs directly on metal substrates. Herein, the current development of direct growth technique and its applications were summarized.

\section{Direct growth of CNTs on buck metal substrates}

With respect to isolating ceramic materials, an important drawback of metal substrate is that the elevated temperature involved in CNT growth by CVD may activate the diffusion of the 
catalyst material into the metallic substrate, which inhibits its activity. To overcome this problem, one possible strategy is to employ pure catalytic metal or alloys containing at least one of these well known catalyst materials as substrates. However, if the substrate selection is constrained to specific metals not including the known catalyst materials, other solutions must be explored. An alternative effective choice is to deposit a thin barrier layer that restrains the diffusion reaction between catalyst and substrate, while minimizing the effect of this layer on the property of the device.

\subsection{Pure catalytic metal or alloys containing at least one of these well known catalyst materials as substrates}

It is accepted that the most common and effective catalysts are $\mathrm{Fe}, \mathrm{Co}, \mathrm{Ni}$ and their alloys. In order to deposit CNTs on these metal foils, nucleation site formation and density on the foil surface are crucial. Du et. al investigated pure Ni as substrate to grow CNTs without any pretreatment (Du \& Pan, 2005). It was found that nickel nanoparticles as nucleation sites for CNT growth come from the fragmentation of nickel surface. However, in most reports, the grown CNTs on pure metal substrates were spaghetti-like, showing low density and weak control of the nanotube growth knetics, even though modifying the surface properties by wet-chemical etching treatments (Mata, et al. 2010), polishing with different roughness (Reddy, et al. 2006). Compared with single catalytic metal, using alloy foils containing at least one of these well known catalyst materials, such as stainless steel (Masarapu \& Wei, 2007; Baddour, et al. 2008), mumetal (Benito \& Lefferts, 2010) and inconel (Talapatra, et al. 2006), as substrates have generated a higher density of CNTs, which may be related to other experiments that an alloy or intermetallic compound containing catalytic and non-catalytic elements assists the formation of a high density of nucleation sites on silicon substrates (Cui, et al. 2003; Zhang, et al. 2006). As it is known that, the role of catalyst and its interaction with the substrate is a key issue of CNT growth. The chemical composition and thermal stability of the substrate at the growth temperature should aquire important consideration for CNT growth. The chemical nature of the substrate under growth conditions should be such that it neither allows the catalyst to diffuse into its bulk, nor spreads out and forms a continuous film. For some Ni-, Co-, Fe- based superalloys, in situ formation of a conductive passivation oxide layer on the surface of these superalloys played an important role in stabilizing nanoclusters of $\mathrm{Fe}$ catalyst under typical growth conditions (Bult, et al. 2009 \& Pal, et al. 2010). On the other hand, introducing an insulating thin buffer layer (such as $\mathrm{Al}_{2} \mathrm{O}_{3}$ ) between the extra catalyst and metallic substrate, where the buffer layer was too thin to form an insulating barrier on the metallic plate, was suggested to obtain relative higher density and quality of CNT forest (Gao, et al. 2008 \& Martinez-Latorre, et al. 2009 \& Lepro, et al. 2010). Moreover, single- and double-walled carbon nanotube forests could be synthesized successfully on various alloys spaning many strandard metals, such as Inconel 601, YEF 426, NiCr, YEF 50, and SUS 310S, covering a wide range of Ni-Fe-Cr compositions, as shown in Fig. 1 (Hiraoka, 2006). Apart from the chemical compostion of substrate, pretreatment of the alloy substrates, especially for that no any other catalyst introduced, significantly affected the efficiency of CNT growth on the metallic substrates. It was reported that surface roughness variation of the alloy by polishing might change the surface chemistry, resulting in inhomogeneous growth of CNTs (Oye, et al. 2010). 

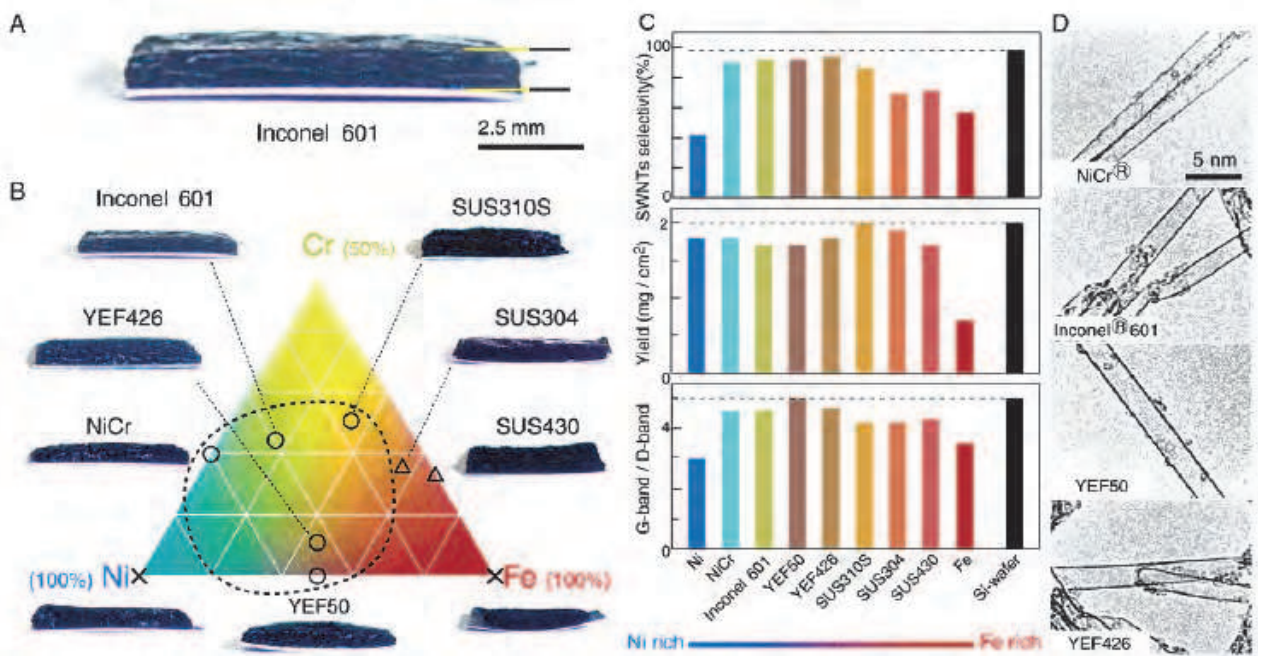

Fig. 1. Direct growth of CNT forests on Ni-Cr-Fe alloys with water-assisted CVD. (A) A photograph of a SWNT forest synthesized on Inconel 601. (B) Correlation between components of Ni-Cr-Fe alloys and photographs of CNT forests grown on them. Symbols indicate the level of SWNT selectivity (O high selectivity; $\geq$ medium selectivity; · low selectivity). (C) A family of histograms showing selectivity of SWNTs, yield per $\mathrm{cm}^{2}$, and Gband/D-band ratio of Raman spectra. (D) TEM images of SWNTs synthesized on Ni-based alloys. (Hiraoka, 2006)

\subsection{Other metals as substrates}

In current electrical and electronic industries, $\mathrm{Cu}$ is the most popular raw material due to their high electric and thermal conductivity with relatively low cost. Thus, it is very interesting to directly grow CNTs on $\mathrm{Cu}$ substrate. It is known that $\mathrm{Cu}$ can act as effective catalyst for CNT growth under certain conditions (Gan, et al. 2001 \& Qin, et al. 2004). However, the grown carbon nanostructures catalyzed by $\mathrm{Cu}$ are spaghetti-like and the catalytic activity of copper is accepted to be much lower than Fe, Co and Ni (Zhang, 2010). Therefore, it seems necessary to introduce other more active catalyst to grow dense aligned CNTs on copper substrate. Directly deposition of catalyst on $\mathrm{Cu}$ substrate is an obvious choice. However, as discussed above, $\mathrm{Cu}$ is not an efficient catalyst for CNT growth and easy to form a solid solution with the common catalysts (especially for $\mathrm{Ni}$ ) at high temperature. The diffusion between catalyst and copper substrate may induce the loss of catalyst. Thus, the catalyst layer should be thick enough to guarantee enough unaffected catalyst residues to catalyze CNT growth (Singh, 2002 \& Yin, 2008), meanwhile, some authors reported that thicker catalyst layers resulted in larger diameter of grown CNTs (Atthipalli, 2011). Therefore, adding a diffusion barrier layer between catalyst and copper substrate is a promising and preferable choice for high-quality aligned CNT growth, although this may increase the contact resistance between CNTs and Cu substrate in some content. A thin layer of alumina has been used as diffusion barrier in most literatures. Lin et al. investigated the effect of the deposition method and thickness of alumina layer on the quality of CNT growth systematically, infering that a well-controlled conformal alumina 
support layer played an important role for the aligned CNT growth with high quality and reproducibility (Lin, et al., 2010). Other ceramic materials, such as $\mathrm{TiN}, \mathrm{In}_{2} \mathrm{O}_{3}: \mathrm{Sn}$ (ITO), and $\mathrm{SiN}_{x}$, were also examined as effective barrier, inferring that the extent of CNT coverage depended on the barrier layer quality (Garc1'a-Ce'spedes, et al., 2009). Apart from ceramic materials, some metals, such as Ti (Sung, et al., 2008), Cr, Au, Ta (Nessim, et al., 2009 \& 2010), Pa (Nessim, et al., 2010), Al (Burt, et al., 2009 \& Kavian, et al., 2011), and so on (Wang, et al., 2003 \& Kim \& Gangloff, 2009), were also used as efficient barrier layers or substrates directly. Although CNT growth on these substrates or underlayers was affected by many factors, understanding the coupled influences of barrier layer thickness, grain size, and catalyst dewetting is an important step in development of a more complete understanding of CNT growth mechanisms.

\subsection{Applications of CNTs directly grown on bulk metal substrate}

Due to a high aspect ratio geometry, small tip radius, good chemical stability, low coefficient of thermal expansion, high thermal and electrical conductivity and mechanical strength, CNTs have attracted great interest as thermal management materials for microelectronic packaging, electrode materials for use in energy storage cells and supercapacitors, field emission (FE) electron sources for use in flat panel displays, e-beam lithography equipment, $x$-ray sources, and vacuum microwave amplifiers, and so on. For these applications, as discussed above, high electrical and thermal conductivities are required, which usually needs a conductive substrate to connect with CNTs. Compared with the external connections, the biggest benefit for direct growth technique of CNTs on metal substrate is that can reduce the contact resistance and form an ohmic connection between CNTs and metal substrate, which is crucial for electronic devices. Thus, it is expected to have a significant advance toward the goal of replacing external metal conections with CNTs, such as CMOS-compatible processes, by direct growth technique (Nessim, et al., 2009 \& Kim, et al., 2010). Experimental results indicated electrical contact through the CNT carpet to the metallic substrate $(\mathrm{Cu})$ by direct growth with an approximate resistance of $35 \mathrm{k} \Omega$ for multiwall CNT carpets taller than two micrometers (Nessim, 2009). Talapatra et al. further certified that the average total contact resistance of aligned CNTs directly grown on inconel by a vapour-phase catalyst delivery CVD method, measured over many samples (typical pattern size $=70 \mu \mathrm{m} \times 70 \mu \mathrm{m}$, height $=50 \mu \mathrm{m})$, was even as low as about $500 \Omega$. The power density for the double-layer capacitors fabricated using the Inconel substrate with directly grown aligned nanotubes as electrodes was about $7 \mathrm{~kW} \mathrm{~kg}^{-1}$ even at a high scan rate of 1000 $\mathrm{mV} \mathrm{s}^{-1}$ (Talapatra, et al., 2006). Due to the good bonding and excellent conductivity by interface-controlled growth of CNTs directly on Cu current collectors, Li ion battery using the novel directly grown binder-free CNTs structure as anode showed very high specific capacity, almost three times as that of graphite, excellent rate capability even at a charging/discharging rate of $3 \mathrm{C}$, and no capacity degradation up to 50cycles (Lahiri, ea al., 2010). The CNT-based field emitters, prepared on metallic substrates by direct thermal chemical vapor deposition, exhibited a very low turn-on field, high emission current, long time stability and good resistance to degradation in high-field, long-time exposure (Mauger, et al., 2004 \& Sung, et al., 2008 \& Mahanandia, et al., 2009 \& Yi \& Yang, 2010 \& Li, et al., 2010 \& Lahiri, et al, 2010). Furthermore, Zhang, et al. indicated that coiled carbon nanosturctures with more defects by direct growth exhibited better field emission properties 
than straight CNTs (Zhang, et al., 2010). Several studies have revealed that CNTs have unusually high thermal conductivity in their axial direction (Berber, et al., 2000 \& Kim, et al., 2010). Thus, one promising application of CNTs in microelectronics is to use vertically aligned CNT arrays as novel thermal interface materials (TIMs). Direct synthesis of vertically aligned CNT TIM layer on the backside of a silican chip is not compatible with current electronic packaging systems. Instead vertically aligned CNT synthesis on metallic substrate, especially for copper, is preferred. The TIM, made up of a thin copper foil covered with Cr-Au-MWCNT on both sides, showed a thermal resistance as low as $12 \mathrm{~mm}^{2} \mathrm{~K} / \mathrm{W}$ (Wang, et al., 2007). Recently, Lin, et al. developed a novel assembling process of incorporating carbon nanotubes as TIM for heat dissipation by synthesizing vertically aligned CNTs on a copper substrate and chemically bonding the carbon nanotubes to a silicon surface. Experimental results indicated that such an interface modification improved the effective thermal diffusivity of the carbon nanotube-mediated thermal interface by an order of magnitude and conductivity by almost two orders of magnitude (Lin, et al., 2010). Due to the retained mechanical flexibility of the metallic substrate (such as stainless steel) after CNT forest synthesis and its renewability and low cost, direct growth of CNTs on metallic substrate becomes a promising approach for industrial production of CNTs, CNT yarns and sheets (Baddour, et al., 2010 \& Lepro', et al., 2010 \& Iijima, 2011).

\section{Direct growth of CNTs on metal powders}

Since their discovery, carbon nanotubes have been regarded as an ideal reinforcement for composites to overcome the performance limits of conventional materials, due to their excellent mechamical and physical properties. Many research efforts have dealt with $\mathrm{CNT}$ /polymer composites, which exhibit a tremendous strengthening effect for the composites (García, et al., 2007). However, the results in metals are not as encouraging as those in polymer. This is mainly due to the difficulties in achieving homogeneous dispersion of CNTs in metal matrix and good interfacial bonding between CNTs and metal matrix. So far, nearly all the efforts were made through powder metallurgy route, which involved

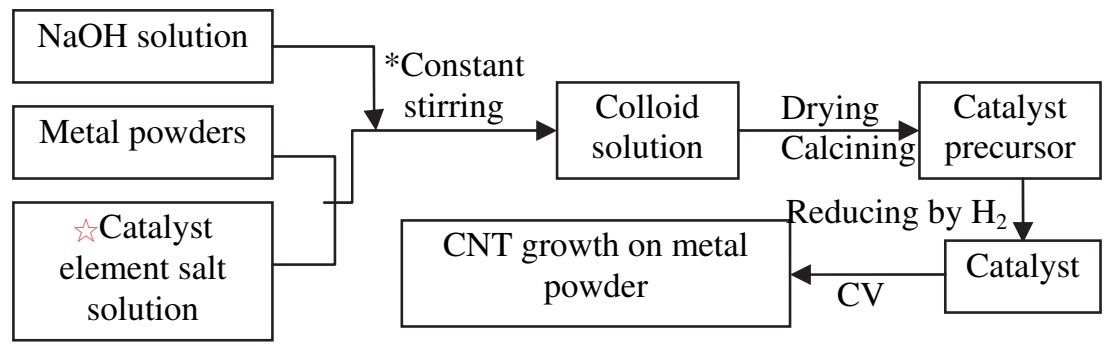

\footnotetext{
$\checkmark$ For $\mathrm{Ni}$ catalyst, the catalyst element salt is $\mathrm{Ni}\left(\mathrm{NO}_{3}\right)_{2} \bullet 6 \mathrm{H}_{2} \mathrm{O}$; For Ni/Y catalyst, the catalyst element salt is a mixture of $\mathrm{Ni}\left(\mathrm{NO}_{3}\right)_{2} \bullet 6 \mathrm{H}_{2} \mathrm{O}$ and $\mathrm{Y}\left(\mathrm{NO}_{3}\right)_{3} \bullet 6 \mathrm{H}_{2} \mathrm{O}$

*For Mg supported catalyst, metal powders mixed with $\mathrm{NaOH}$ solution firstly. The salt solution was added to the mixed solution dropwise under constant stirring
}

Fig. 2. Schematic diagram of the CNT growth directly on metal powders 
mixing of CNTs with metal powders by ball milling or chemical process (Cha, et al., 2005 \& Kim, et al., 2006). In the above methods, CNTs was inclined to be damaged and lose their initial properties during the mechanical milling or their functionalization process. Alternatively direct synthesis of CNTs in metal matrix composites may overcome the problems associated with conventional methods and achieve homogeneous distribution of CNTs and good interfacial bonding between CNTs and metal matrix. In this section, we will summarize our recent progress in this field. Several metal powders, such as $\mathrm{Al}, \mathrm{Cu}, \mathrm{Mg}, \mathrm{Ag}$, have been proved as effective support for CNT growth. The catalyst dispersed on these metal powders was prepared by deposition-precipitation. The experimental procedure was described in Fig. 2. CNT growth was performed by a simple CVD process.

\subsection{Aluminum powder}

As mentioned above, aluminum can be used as effective underlayer or substrate for catalyst deposition, probably due to its easy formation of a passivation oxide layer on the surface of $\mathrm{Al}$ (Liu, et al., 2008). In our study, Ni nanoparticles were homogeneously deposited on $\mathrm{Al}$ particle surface by a direct deposition-precipitation method. Fig. 3 displays transmission electron microscopy (TEM) images of representative Ni-Al catalyst powders. Almost all $\mathrm{Al}$ powders are evenly decorated by several Ni nanoparticles. It is found that catalytic particles of different sizes can be formed by varying the reduction temperature, which thus controls the diameter of the growing tubes. When reducing the catalyst precursor at $400{ }^{\circ} \mathrm{C}$ for $2 \mathrm{~h}$, the diameter of the Ni particles ranged from 5 to $20 \mathrm{~nm}$. It can be clearly seen from Figure $3 \mathrm{~b}$ that Ni nanoparticles with even diameters are homogeneously dispersed on the surface of the $\mathrm{Al}$ powders.

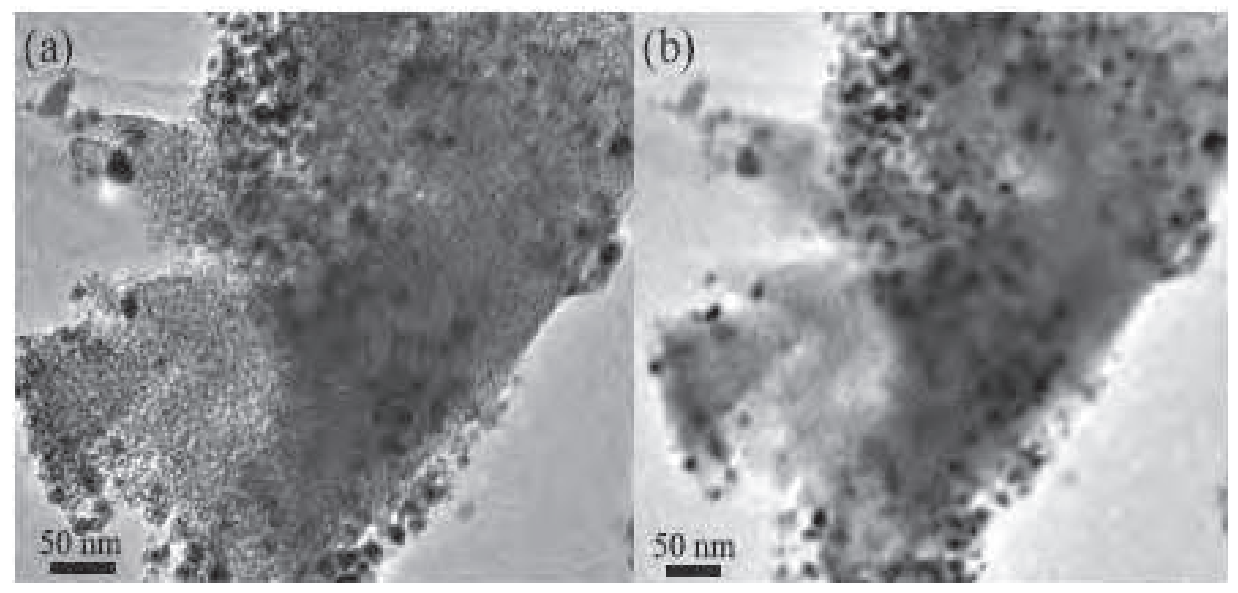

Fig. 3. Microstructures of the $\mathrm{Ni}-\mathrm{Al}$ catalyst powders, in which the Ni nanoparticles with a narrow diameter distribution are homogeneously dispersed on the surface of the $\mathrm{Al}$ powder. a) TEM image of a $\mathrm{Ni}-\mathrm{Al}$ catalyst powder, obtained by reducing the catalyst precursor at $400^{\circ} \mathrm{C}$ for $2 \mathrm{~h}$ (scale bar: $50 \mathrm{~nm}$ ). b) TEM image of a Ni-Al catalyst powder, showing that the gray $\mathrm{Al}$ powder is evenly decorated by several black Ni nanoparticles (scale bar: $50 \mathrm{~nm}$ ). 

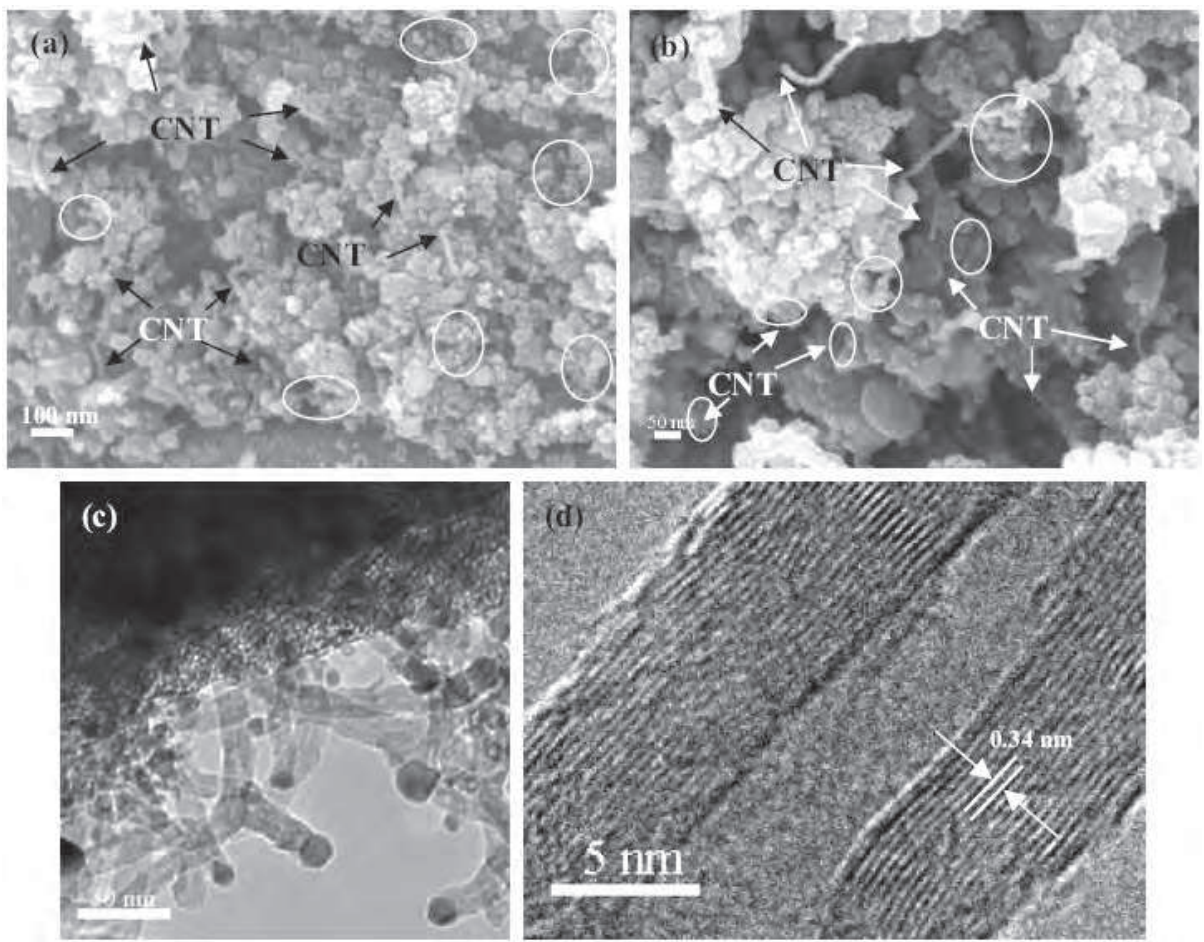

Fig. 4. a) Scanning electron microscopy (SEM) image of a CNT(Ni)-Al composite powder (scale bar: $100 \mathrm{~nm}$ ). b) Enlarged SEM image of several typical CNTs (indicated by arrows) dispersed in the $\mathrm{Al}$ powders, the locations indicated with ellipses show the network structures between CNTs and Al powders (scale bar: $50 \mathrm{~nm}$ ). c) Low-magnification HRTEM image of a CNT-Al composite powder (scale bar: $50 \mathrm{~nm}$ ). d) High-resolution TEM (HRTEM) image of a typical CNT, showing a well-graphitized multiwalled nanotube (scale bar: $5 \mathrm{~nm}$ ).

Fig. 4a shows a low-magnification scanning electron microscopy (SEM) image of homogeneously dispersed CNTs within the Al powders. The surfaces of the walls of the asgrown CNTs are clean, and their diameters range from 5 to $25 \mathrm{~nm}$. In addition, metallic nanoparticles are visible at the tips of the CNTs. The most important feature of our process is that the CNTs are synthesized into the $\mathrm{Al}$ powders in situ. The morphology of the $\mathrm{CNT}(\mathrm{Ni})-\mathrm{Al}$ powders shows an ideal composite microstructure, displaying spherical morphologies with CNTs homogeneously dispersed into the powders. It is also found that the density and length of the CNTs, or the CNT content of the composite powders, can be tuned by adjusting the experimental parameters, such as the growth time and the Ni content in the Ni-Al catalyst. With a shorter time and lower Ni content, shorter and sparser CNTs can be obtained in the $\mathrm{Al}$ powders. Figure $4 \mathrm{~b}$ is an enlarged SEM image of several typical CNTs (indicated by arrows) dispersed in the Al powders. It can be distinctly observed that the CNTs are not agglomerated at all. Moreover, we have noticed that some locations, marked with ellipses in Figure $4 \mathrm{~b}$, form network structures between the CNTs and the Al powders. 
The microstructure details of the $\mathrm{CNT}(\mathrm{Ni})-\mathrm{Al}$ composite powders were investigated with high-resolution TEM (HRTEM). The low-magnification HRTEM image in Figure 4c further verifies that the tips of the CNTs encapsulate metallic particles. An HRTEM image of a typical CNT, as seen in Figure $4 \mathrm{~d}$, demonstrates that the CNTs are well-graphitized multiwalled nanotubes. The graphitic sheets of the CNTs (see Fig. 4d) are apparent, and the interlayer spacing between the sheets is $0.34 \mathrm{~nm}$, consistent with the ideal graphitic interlayer space $(0.34 \mathrm{~nm})$. To determine the length of the as-grown CNTs, dilute nitric acid was used to remove the $\mathrm{Al}$ from the composite powders. TEM analysis indicates that the CNTs are easily entangled after removing $\mathrm{Al}$ as a result of strong van der Waals forces between them, and their lengths range from 1500 to $2500 \mathrm{~nm}$.

The CNT(Ni)-Al bulk composite was prepared by pressing and sintering the CNT(Ni) composite powders directly. The microstructure of the composite was investigated by TEM. In the low magnification TEM image of Figure 5a, we see only some black Ni nanoparticles (indicated by arrows) distributed evenly within the $\mathrm{Al}$ grains. When investigating the area around the black Ni nanoparticles in detail by high-magnification TEM, it is found that the CNTs with encapsulated Ni nanoparticles are dispersed very homogeneously within the $\mathrm{Al}$ matrix (as seen in the inset of Fig. 5a). In particular, the TEM image (Fig. 5a, inset) shows that the interfaces of the CNTs and Al bond well, and that no reactant is formed by the present technique. Furthermore, the Al grains reinforced by CNTs present a very low location density. Figure $5 \mathrm{~b}$ is an SEM image of the composite fracture surface, which shows CNTs with an obviously tubular structure (Fig. 5b, inset). Moreover, it can be observed that the CNTs are dispersed very well into the Al matrix, and some CNTs are pulled-out or broken (marked with triangles), which indicates that the load transfer from the matrix to the nanotubes is sufficient to fracture the nanotubes.
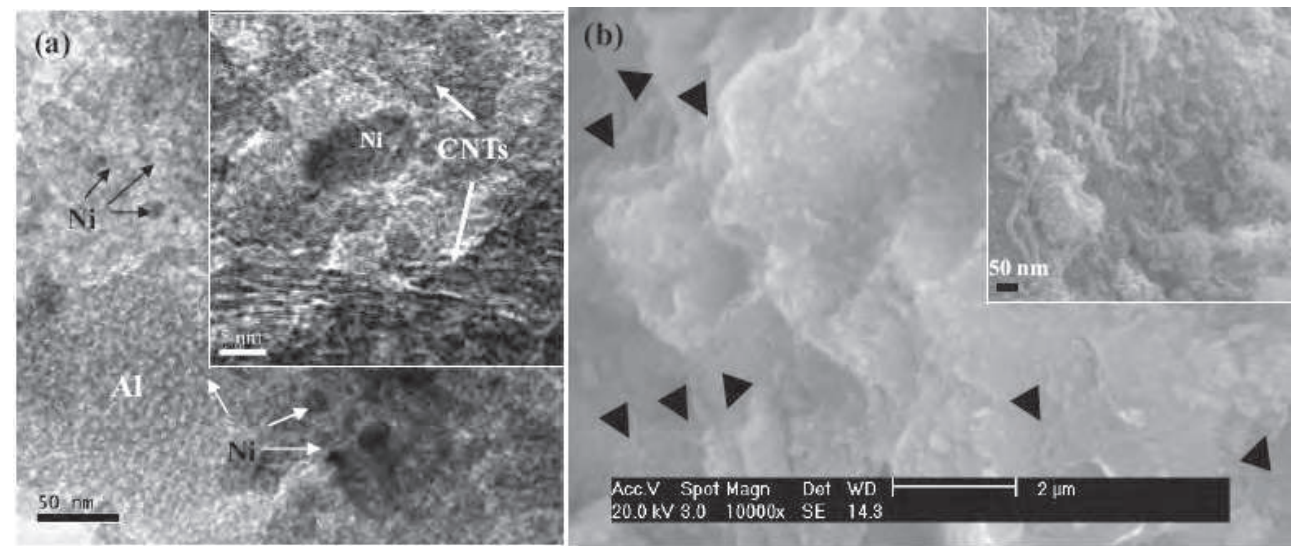

Fig. 5. a) TEM image of a CNT(Ni)-Al matrix bulk composite, showing the homogeneously dispersed $\mathrm{CNT}(\mathrm{Ni}$ ) within the $\mathrm{Al}$ matrix (scale bar: $50 \mathrm{~nm}$, scale bar of inset: $5 \mathrm{~nm}$ ). b) SEM image of the fractured surface of a CNTs $(\mathrm{Ni})$ - Al matrix bulk composite, showing the existence of pulled-out and broken CNTs (scale bar of inset: $50 \mathrm{~nm}$ ).

Table 1 presents a comparative study of hardness and tensile strength values of the composite and two other typical materials that were fabricated by the same procedure (i.e., pressing, sintering, and re-pressing). The density of the CNT(Ni)-Al bulk composite (c) was 
measured by the Archimedes principle as $2.50 \mathrm{~g} \mathrm{~cm}^{-3}$, which is about $96 \%$ of the theoretical density $\left(2.6 \mathrm{~g} \mathrm{~cm}^{-3}\right)$ of $\mathrm{Al}$ with a $5 \mathrm{wt} \%$ CNT reinforcement, and about $93 \%$ of the matrix density. The hardness $(0.65 \mathrm{GPa})$ and tensile strength $(398 \mathrm{MPa})$ of the $\mathrm{CNT}(\mathrm{Ni}) / \mathrm{Al}$ composites (c) are 4.3 and 2.8 times that of the pure Al matrix (Table 1). To further verify the strengthening effect of the in situ synthesized CNTs for the bulk composites, the same composite was also prepared by a traditional method, which involved the preparation of CNT(5 wt \%)-Ni (1 wt \%)-Al composite powders by ball-milling the CNTs and the Ni-Al powders, pressing, and sintering of the composite powders. According to Table 1, the hardness and tensile strength of the in situ synthesized $\mathrm{CNT}(\mathrm{Ni})-\mathrm{Al}$ composites (c) are 2.0 and 1.8 times, respectively, that of the composites with a similar composition (b). This remarkable strengthening is caused by the dispersion strengthening of the homogeneously dispersed CNTs and Ni nanoparticles. Besides, the retention of the perfect structure gives the CNTs their extreme hardness (62-150 GPa), whereas molecular-level homogenous mixing between $\mathrm{CNTs}$ and Al powders brings about strong interfacial strength between $\mathrm{CNTs}$ and $\mathrm{Al}$ powders. Both factors contribute to the tremendous enhancement of the overall hardness and strength of the composites. The strong interfacial strength between CNTs and Al powders that resulted from very good homogeneous dispersion of CNTs in Al powders is especially important to improve the composite performance, because it can cause high load translation during tensile processes (as suggested by pulling out and broken of CNTs in Fig. 5b) and thus raise the fracture energy and the tensile strength of the composites. As for the CNT-Al matrix composite produced by a traditional method, the interfacial strength between CNTs and Al powders can not be expected to be high because of the mere mixing of the CNTs and the Al matrix. Moreover, the high-temperature generated by high-energy ball milling and plasma spraying damages the perfect structure of CNTs. As a result, the reinforcement effect of the CNTs on the composites is not very outstanding (Kuzumaki, et al., 1998 \& Laha, et al., 2004 \& George, et al., 2005). Compared to reinforcements such as $\mathrm{Al}_{2} \mathrm{O}_{3}$ (Huang, et al., 2003 \& Kang, et al., 2004), $\mathrm{SiC}$ (Moreno, et al., 2006), $\mathrm{TiB}_{2}$ (Huang, et al., 2005), aluminum borate whiskers (Zhu \& Lizuka, 2003), TiN (Shyua, et al., 2002), and others used for Al matrix composites (Zambona, et al., 2004 \& Tang, et al., 2003), the strengthening effect of the CNT reinforcement is the strongest ever reported.

\begin{tabular}{lcccc}
\hline Material & $\begin{array}{c}\text { Theoretical } \\
\text { density } \\
{\left[\mathrm{g} \mathrm{cm}^{-3}\right]}\end{array}$ & $\begin{array}{c}\text { Measured } \\
\text { density } \\
{\left[\mathrm{g} \mathrm{cm}^{-3}\right]}\end{array}$ & $\begin{array}{c}\text { Hardness } \\
{[\mathrm{GPa}]}\end{array}$ & $\begin{array}{c}\text { Tensile strength } \\
\text { at RT } \\
{[\mathrm{MPa}]}\end{array}$ \\
\hline Pure Al & 2.7 & 2.69 & 0.15 & 140 \\
CNT(5 wt \%)-Ni (1wt \%)-Al & 2.6 & 2.48 & 0.32 & 213 \\
matrix composite [a] & 2.6 & 2.50 & 0.65 & 398 \\
CNT(5 wt \%)-Ni (1 wt \%)-Al & & & & \\
matrix composite [b] & & & \\
\hline
\end{tabular}

[a] Obtained by ball-milling CNTs and Ni-Al powders. [b] Obtained by in situ CVD synthesis.

Table 1. Comparative study of the CNTs(Ni)-Al matrix bulk composite and two typical materials with respect to density, hardness and tensile strength 


\subsection{Copper powder}

From the binary phase diagram, it is known that $\mathrm{Cu}$ is inclined to form solid solution with $\mathrm{Ni}, \mathrm{Co}$ and Fe. Experimental results showed that there were almost no carbon deposits synthesized by CVD using $\mathrm{Ni}$ catalyst nanoparticles deposited on $\mathrm{Cu}$ particle surface (prepared by deposition-precipitation) at any conditions. XRD analysis indicated that $\mathrm{Ni}$ and $\mathrm{Cu}$ had alloyed completely by diffusion at even lower than $500^{\circ} \mathrm{C}$. It is also impossible to deposit a diffusion barrier layer on $\mathrm{Cu}$ particle surface, like that on buck $\mathrm{Cu}$ substrate. Thus, the only alternative way is to prepare a new kind of stable and effective catalyst, which is not affected by the underlayer materials. Herein, a novel Y stabilized Ni catalyst was successfully prepared by deposition-precipitation. XRD examination of the Ni-Y catalyst reduced at $500^{\circ} \mathrm{C}$ indicated that there were no reactions between $\mathrm{Ni}$ and $\mathrm{Cu}$. However, we did not found any phase peaks that possibly contained Y element (Fig. 6a). Fig. $6 \mathrm{~b}$ shows the TEM images of the Ni-Y catalyst with a weight ratio of 4:1 (Ni:Y) reduced at $500^{\circ} \mathrm{C}$. It can be seen that the crystal lattice structure of the catalyst nanoparticle is very complex. The basic structure of the nanoparticle is Ni crystal lattice, while, some very small crystals with larger interplanar spacing (about $0.3 \mathrm{~nm}$, which is similar to that of the (111) plane of $\mathrm{Y}_{2} \mathrm{O}_{3}$ ) seems to insert in the basic crystal lattice, as indicated by arrows in Fig. 6b. Thus, the whole particle demonstrates a mixture of $\mathrm{Ni}$ and $\mathrm{Y}_{2} \mathrm{O}_{3}$ (very small $\mathrm{Y}_{2} \mathrm{O}_{3}$ crystals embedded in $\mathrm{Ni}$, which may be responsible to that why the XRD cannot detect any phases containing $\mathrm{Y}$ ). The more $\mathrm{Y}$ content in the composite catalyst, the more stable the catalyst is. However, $\mathrm{Y}\left(\mathrm{Y}_{2} \mathrm{O}_{3}\right)$ itself does not have any catalytic activity for CNT growth. Too Y loading will degrade the general activity of the novel composite catalyst.
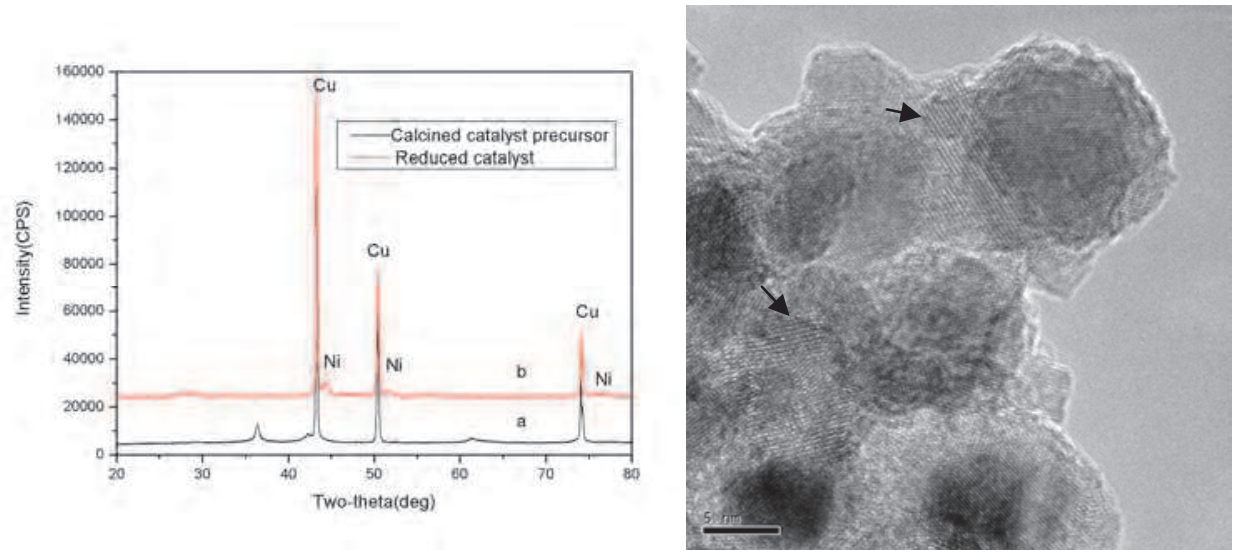

Fig. 6. (a) XRD analysis of the Ni/Y catalyst (Ni:Y $=4: 1)$ precursor calcined at $300^{\circ} \mathrm{C}$ and $400^{\circ} \mathrm{C}$ for $2 \mathrm{~h}$ respectively under $\mathrm{N}_{2}$ atmosphere and catalyst reduced at $500^{\circ} \mathrm{C}$ for $2 \mathrm{~h}$ under $\mathrm{H}_{2}$ atmosphere (b) TEM image of the catalyst after reduction

In order to prepare $\mathrm{Cu}$ composite with homogeneous $\mathrm{CNT}$ dispersion, the first step is to obtain homogeneously dispersed active catalyst on the $\mathrm{Cu}$ particle surface (Fig. 7a) and then grow CNTs with controllable content and quality by CVD (Fig. 7.b). The resulting powder was termed as in situ CNT(Ni/Y)-Cu composite powder. Since some ceramic materials are suggested to be suitable as catalyst support, the in situ CNT synthesis has been widely used in the fabrication of ceramic matrix composite, which develops homogeneous CNT dispersion in the matrix (Peigney, et al., 2002). However, most of the CNTs are located on 
the surface of ceramic powders, which inhibits the diffusion of matrix materials across or along the powder surfaces; thus, sintering cannot easily proceed without damaging the CNTs or removing them from the powder surface. Even if sintering is successful, CNTs are mostly located at grain boundaries of the matrix and are insignificant in improvement of material performance. Furthermore, the CNTs should be short enough to avoid entanglement (Balani, et al., 2008). In order to overcome these shortcomings, we introduce the third step effectively to implant CNTs into the $\mathrm{Cu}$ powders. The in situ synthesized $\mathrm{CNT}(\mathrm{Ni} / \mathrm{Y})-\mathrm{Cu}$ composite powders and copper ions from the copper salt $\left(\mathrm{Cu}\left(\mathrm{NO}_{3}\right)_{2} \cdot 2.5 \mathrm{H}_{2} \mathrm{O}\right)$ were added into a minimal amount of ethanol and the solution was heated under constant magnetic stirring until the ethanol was vaporized completely (Fig. 7c). Because the direct grown CNTs are attached on the $\mathrm{Cu}$ particles by metallurgical bond, CNTs can flow with the $\mathrm{Cu}$ particles without separation during the solution mixing by magnetic stirring, which prevents the agglomeration of CNTs. Thus, this unique process combining in situ synthesis of CNTs and a solution mixing can easily obtain a high dispersion of CNTs in metal matrix and a clean interfacial bond between the CNTs and matrix materials. The quantity of copper ions added is equal to that of the in situ $\mathrm{CNT}(\mathrm{Ni} / \mathrm{Y})-\mathrm{Cu}$ composite powders. The powders generated in the third step are generally a mixture, where the $\mathrm{CNT}(\mathrm{Ni} / \mathrm{Y})-\mathrm{Cu}$ composite powders were encapsulated by the basic $\mathrm{Cu}$ salts from decomposition of $\mathrm{Cu}\left(\mathrm{NO}_{3}\right)_{2} \bullet 2.5 \mathrm{H}_{2} \mathrm{O}$ (Fig. 7d). The fourth is the calcination and reduction process to obtain chemically stable crystalline powders (Figure 1e). During this process, the powders become $\mathrm{CNT}(\mathrm{Ni} / \mathrm{Y})-\mathrm{Cu}-\mathrm{CuO}\left(\mathrm{Cu}_{2} \mathrm{O}\right)$ by heating at $300{ }^{\circ} \mathrm{C}$ in air and are then reduced to $\mathrm{CNT}(\mathrm{Ni} / \mathrm{Y})-\mathrm{Cu}$ composite powders under a hydrogen atmosphere. Finally, the composite powers are hot pressed at $500{ }^{\circ} \mathrm{C}$ for $30 \mathrm{~min}$ in a vacuum of $10^{-6}$ torr with an applied pressure of 50MPa.
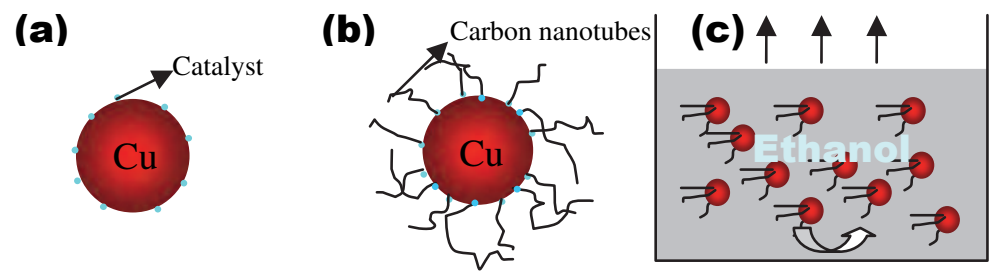

(d)

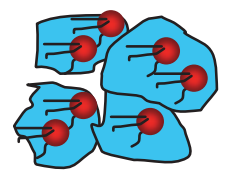

(e)

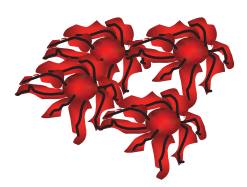

Fig. 7. Schematic illustration of the fabrication of $\mathrm{CNT}(\mathrm{Ni} / \mathrm{Y})-\mathrm{Cu}$ composite powders: a) formation of active catalyst nanoparticles scattered homogeneously on the surface of $\mathrm{Cu}$ powder by deposition-precipitation followed by calcination and reduction processes, $b$ ) in situ synthesis of CNTs in the matrix by CVD, c) mixing a Cu salt and the in situ CNT(Ni/Y)$\mathrm{Cu}$ composite powders in ethanol, d) vaporization of the solvent by heating under constant magnetic stirring, e) calcination and reduction to obtain CNT-implanted Cu matrix composite powders 

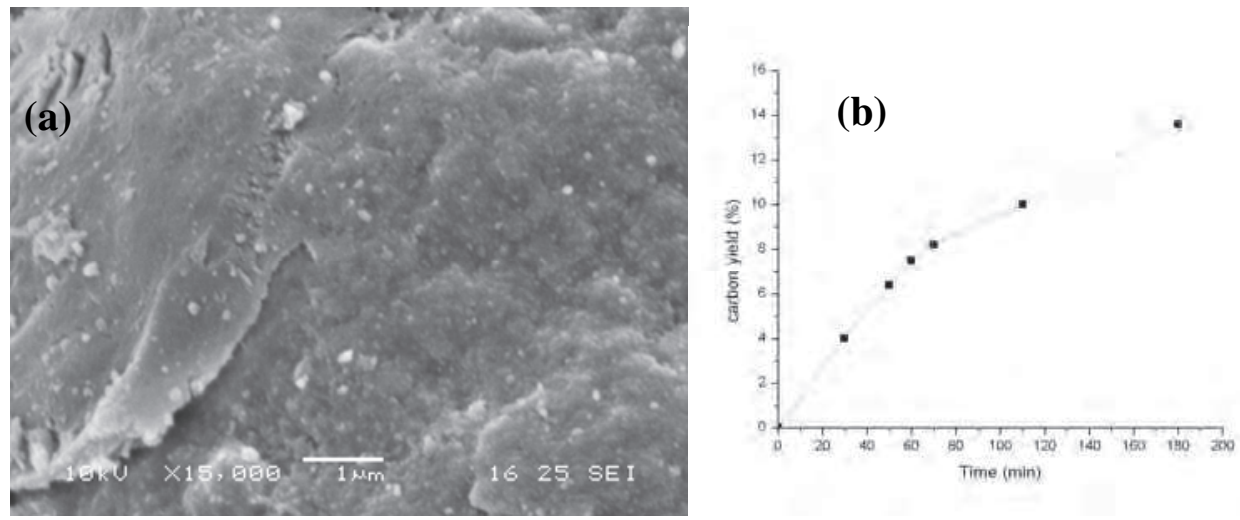

Fig. 8. (a) SEM image of the Ni/Y-Cu catalyst, showing a homogeneous dispersion of Ni/Y catalyst on the surface of $\mathrm{Cu}$ powder; (b) variation of carbon yield with growth time by CVD at $500 \circ \mathrm{C}$ using $2 \% \mathrm{Ni1} \% \mathrm{Y}-\mathrm{Cu}$ catalyst

SEM images show that almost all of the $\mathrm{Cu}$ powders are evenly decorated by Ni/Y composite nanoparticles after the first processing step. Figure 8a displays a highmagnification SEM image of representative $\mathrm{Ni} / \mathrm{Y}$ catalyst supported on $\mathrm{Cu}$ powders (containing $2 \mathrm{wt} . \% \mathrm{Ni}$ and $1 \mathrm{wt} . \% \mathrm{Y}$ ). It can be seen that the catalyst (Ni/Y) nanoparticles with a diameter of about 20-40nm have been homogeneously dispersed on the surface of the $\mathrm{Cu}$ powders. The density and length of the CNTs, or the CNT fraction in the composite powders, can be tuned by adjusting the experimental parameters, such as growth time. Figure $8 \mathrm{~b}$ is a typical growth time-carbon yield curve of the composite powders by CVD at $500^{\circ} \mathrm{C}$ using $2 \% \mathrm{Ni1} \% \mathrm{Y}-\mathrm{Cu}$ catalyst. With longer time, the slope of the time-carbon yield curve is almost stable at first and then decreases, which is similar with previous reports (Venegoni, et al., 2002).

Figure 9a shows a low-magnification SEM image of the in-situ CNT(Ni/Y)-Cu composite powders obtained by CVD. Almost all $\mathrm{Cu}$ particles are decorated by $\mathrm{CNTs}$, displaying spherical morphologies with CNTs highly dispersed into the powders. The most important feature of our process is that the CNTs are synthesized into the $\mathrm{Cu}$ powders in situ, resulting in a relatively firm bonding between $\mathrm{CNTs}$ and $\mathrm{Cu}$ powders. From Figure $9 \mathrm{~b}$, we can observe the direct growth of CNFs on the surface of $\mathrm{Cu}$ powder (indicated by white arrows). The diameter of CNFs ranges from $20-50 \mathrm{~nm}$. A high-resolution transmission electron microscopy (HRTEM) image of a typical CNT, as inserted in Figure 9b, demonstrates the well-graphitized herringbone structure. The graphitic sheets of CNTs are apparent, and the interlayer space between the sheets is similar with the ideal graphitic interlayer spacing $(0.34 \mathrm{~nm})$. It is also found that the surface of the CNTs is not smooth, displaying a zigzag structure.

During the third mixing process, the in-situ composite powder at micrometer level is easy to disperse highly in the solution under constant stirring, and the fluid force can not separate the CNTs and force them to move with the $\mathrm{Cu}$ powders. Furthermore, the $\mathrm{Cu}$ ions at the atomic level are mixed with CNTs in the solution and thus contact with CNTs very well. Figure 10 shows the microstructures of $\mathrm{CNT}(\mathrm{Ni} / \mathrm{Y})-\mathrm{CuO}$ and $\mathrm{CNT}(\mathrm{Ni} / \mathrm{Y})-\mathrm{Cu}$ composite powders. It can be seen that CNTs are located within the powders rather than on the powder surface. The morpholgies of the $\mathrm{CNT}(\mathrm{Ni} / \mathrm{Y})-\mathrm{CuO}$ and $\mathrm{CNT}(\mathrm{Ni} / \mathrm{Y})-\mathrm{Cu}$ composite 
powders show an ideal composite microstructure, which displays a network with CNTs implanted in the $\mathrm{Cu}$ powders. It is also interesting that $\mathrm{Cu}$ is directly synthesized at the surface of neat CNTs, producing CNT-Cu chains instead of agglomerating together to form large particles (see Figure 10b), thus, realizing excellent wetting of the tubes by $\mathrm{Cu}$, separation of the tubes, and excellent dispersion in the matrix.
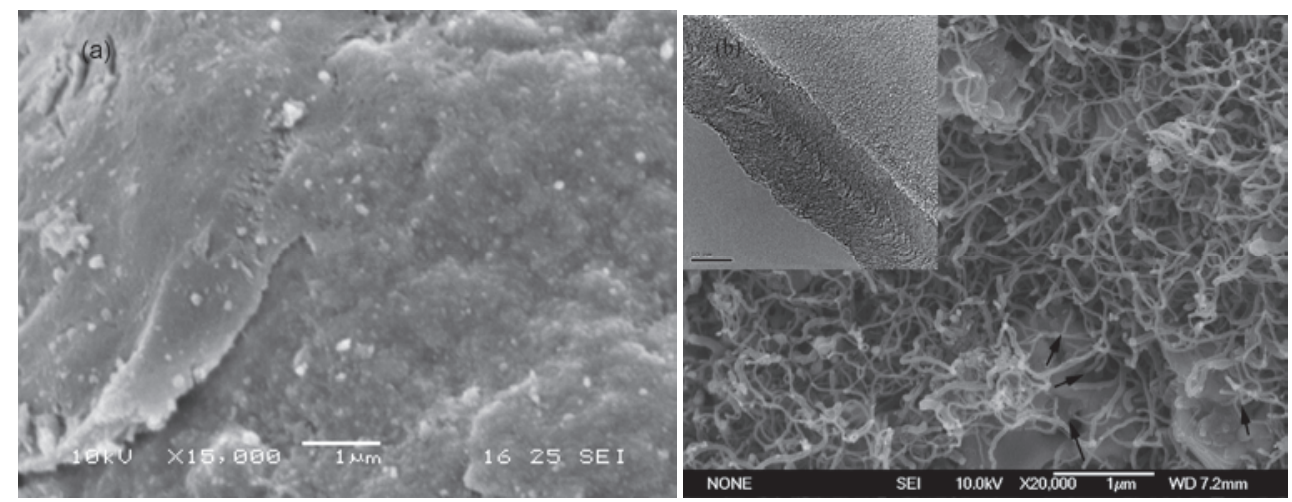

Fig. 9. (a) SEM image of the in-situ CNT(Ni/Y)-Cu composite powders; (b) Highmagnification SEM image of a representative composite powder, the inserted is a HRTEM image of a typical CNT, showing a multi-walled nanotube with herringbone structure
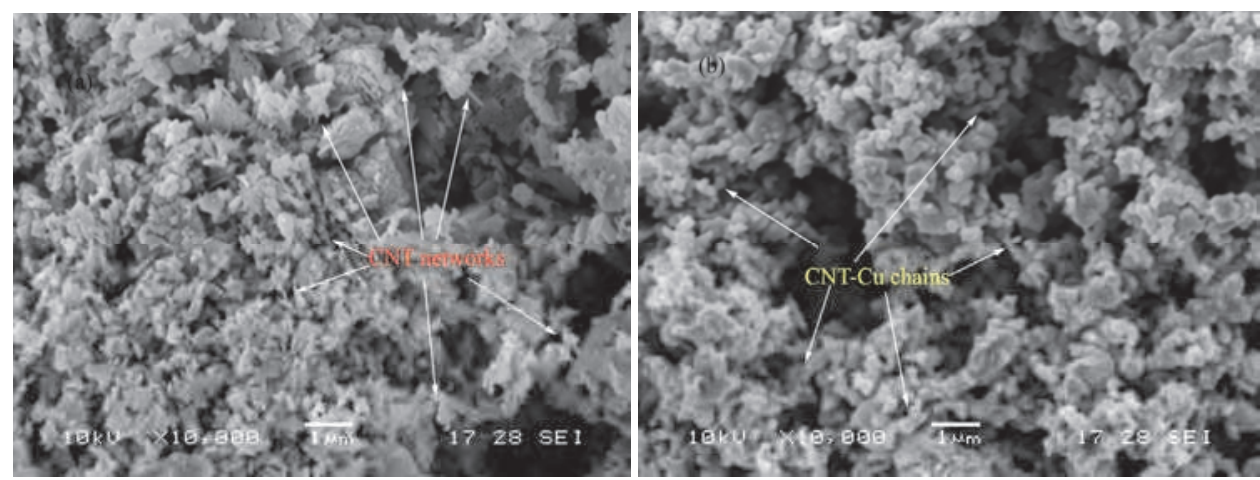

Fig. 10. Microstructures of $\mathrm{CNT}(\mathrm{Ni} / \mathrm{Y})-\mathrm{CuO}$ (a) and $\mathrm{CNT}(\mathrm{Ni} / \mathrm{Y})-\mathrm{Cu}$ (b) composite powders, where the CNTs are homogeneously covered with copper

The final composite powders were consolidated into a bulk CNT(Ni/Y)-Cu composite by a vacuum hot pressing process. Fig. 11a shows a low-magnification SEM micrograph of the $\mathrm{CNT}(\mathrm{Ni} / \mathrm{Y})-\mathrm{Cu}$ composite surface after chemical etching. There are many dark gray particles highly dispersed into the light gray area. High-magnification SEM images indicated that there are many twin striations in the dark gray particles, which is the typical character of crystalline copper (Fig. 11b). These dark gray particles are the original copper particles in the in situ $\mathrm{CNT}(\mathrm{Ni} / \mathrm{Y})-\mathrm{Cu}$ powders, which have been encapsulated completely and not oxidized during the calcination in air. XRD analysis of the calcined powders also indicates the existence of $\mathrm{Cu}$. The inserted picture in Fig. 11b shows a typical boundary 
between the dark gray particles and the gray matrix area. It can be seen that the CNTs are still connected with the $\mathrm{Cu}$ particles, inferring that the CNTs are not separated from the in situ $\mathrm{CNT}(\mathrm{Ni} / \mathrm{Y})-\mathrm{Cu}$ powders during the mechanical stirring or the bonding strength between the CNTs and $\mathrm{Cu}$ support is strong enough to endure the flowing force. The flowing trace of CNTs with the solution can be observed (indicated by white arrow and ellipse). The gray area shows a highly homogeneous distribution of CNTs within the $\mathrm{Cu}$ matrix (Fig. 11c). Particularly, the CNTs form a 3-dimensional (3-D) network within the $\mathrm{Cu}$ grains instead of locating at the grain boundary (Fig. 11c insert).

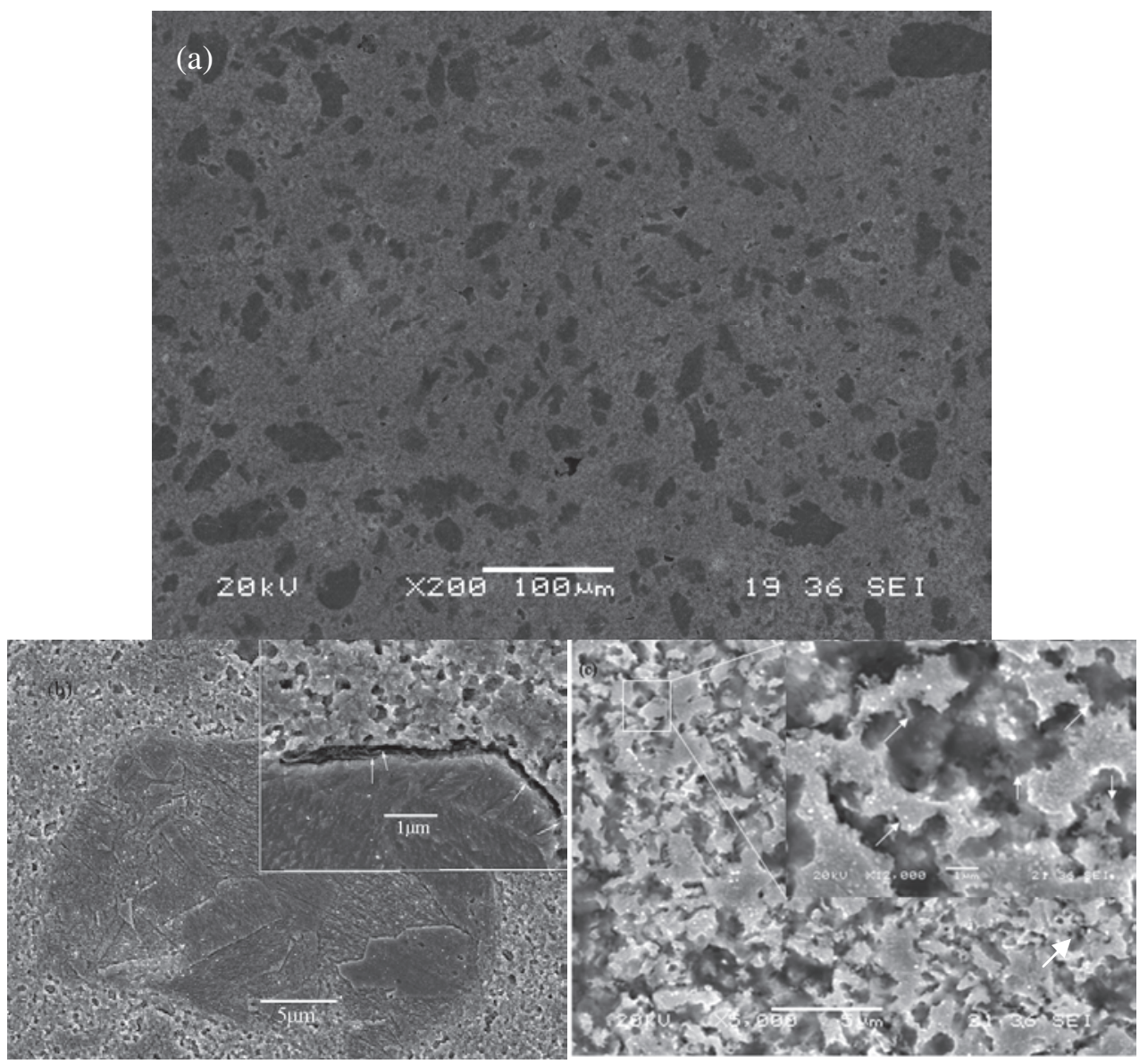

Fig. 11. SEM images of the CNT(Ni/Y)-Cu composite surface after chemical etching, showing homogeneous 3-D distribution of CNTs in the composite.

The mechanical properties of the $\mathrm{CNT}(\mathrm{Ni} / \mathrm{Y})-\mathrm{Cu}$ composite were characterized using compressive tests. As shown in Fig. 12a, the compressive yield strengths of CNT(Ni/Y)-Cu composite were much higher than that of the $\mathrm{Cu}$ matrix, which was fabricated by the same hot pressing process without adding CNT(Ni/Y). A 3.4wt.\% CNT-reinforced Cu composite showed a yield strength of $581 \mathrm{MPa}$, which is more than 3.6 times higher than that of $\mathrm{Cu}$. 
Even with as much as $5.7 \mathrm{wt}$.\% CNTs, the yield strength was still $448 \mathrm{MPa}$, which is 2.8 times higher than that of $\mathrm{Cu}$. The reduction of the properties of the composites with high fraction of CNTs may be due to the local agglomeration of CNTs and low relative density. However, compared with that obtained by traditional methods, the yield strength of the composites with 5.7\%CNTs was still higher, meaning that the agglomeration of CNTs is not serious. By reducing the powder size of $\mathrm{Cu}$ used for catalyst and post treatment of the composites, such as hot extrusion, it has high potential to improve the properties of the composites further. Such research is in the processing. The linear coefficient of thermal expansion (CTE, 30-200 ${ }^{\circ} \mathrm{C}$ ) of the composite with $5.7 \mathrm{wt}$. $\%$ CNTs reduced to $10.1^{*} 10^{-6} /{ }^{\circ} \mathrm{C}$, about $57.7 \%$ the CTE measured on the $\mathrm{Cu}$. As shown in Table 2, the reinforcement efficiency for reduction of CTE of composites, i.e., the effect of a given volume percentage of reinforcement on the matrix, is more than two times that of $\mathrm{W}, \mathrm{Mo}, \mathrm{SiC}$ and diamond (Table 2). This indicates that the composites with high $\mathrm{CNT}$ content have potential as advanced heat sink materials, which requires low CTE, high thermal conductivity and machinability.
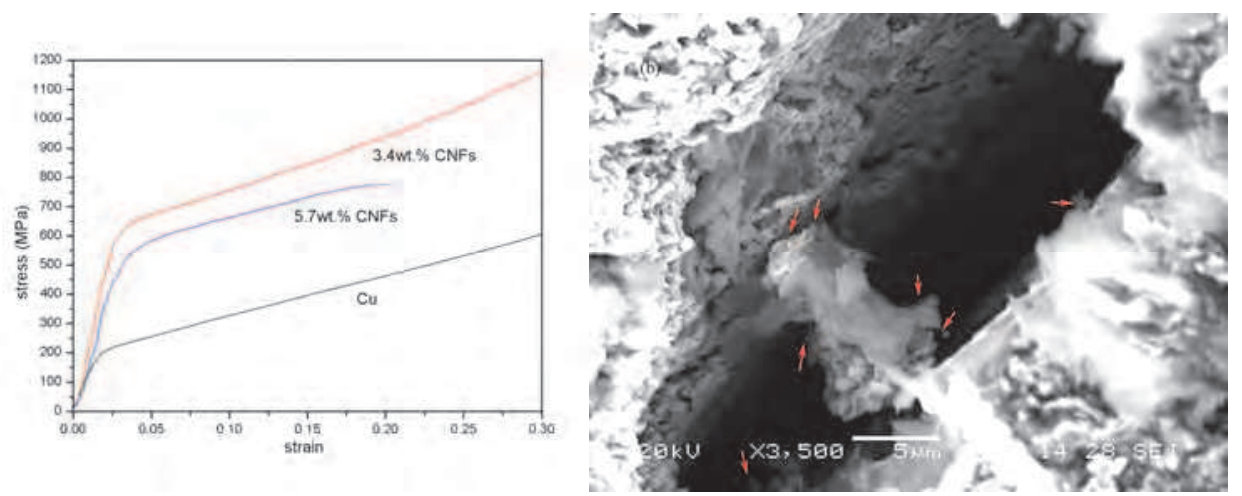

Fig. 12. a) stress-strain curves of $\mathrm{CNF}(\mathrm{Ni} / \mathrm{Y})-\mathrm{Cu}$ composites obtained by compressive testing, and b) SEM image of the crack structure of the composite under compressive testing.

\begin{tabular}{lllll}
\hline matrix & reinforcement & Vol.\% & CTE $\sigma\left(10^{-6} / \mathrm{K}\right)$ & $\begin{array}{l}\text { Efficiency of the } \\
\text { reinforcement R[a] }\end{array}$ \\
\hline $\mathrm{Cu}$ & $\mathrm{SiC}_{\mathrm{p}}(\mathrm{Mo})$ & 40 & 11.5 & 0.81 \\
$\mathrm{Cu}$ & $\mathrm{Diamond}(0.8 \mathrm{Cr})$ & 42 & 11 & 0.84 \\
$\mathrm{Cu}$ & $\mathrm{AlN}$ & 40 & 9.6 & 1.09 \\
$\mathrm{Al}$ & $\mathrm{SiC}_{\mathrm{p}}$ & 50 & 10.8 & 1.06 \\
$\mathrm{Cu}$ & $\mathrm{Mo}$ & $60-85$ & $6.27-9$ & $<0.8$ \\
$\mathrm{Cu}$ & $\mathrm{W}$ & $80-90$ & $5.6-9.1$ & $<0.8$ \\
$\mathrm{Cu}$ & $\mathrm{CNFs}$ & $23[\mathrm{~b}]$ & 10.1 & 1.76 \\
\hline
\end{tabular}

[a] The efficiency of the reinforcement $R=\left(\sigma_{c}-\sigma_{m}\right) / V_{f} \sigma_{m}$.

[b] The density of CNFs is estimated as $1.8 \mathrm{~g} / \mathrm{cm}^{-3}$.

Table 2. The efficiencies of several reinforcement materials for reduction of CTE of composites (Schubert, et al., 2008 \& Wu, et al., 2006 \& Geffroy, et al., 2007 \& Lee, et al., 2007) 
Such excellent strengthening by CNT reinforcement was due to the high dispersion of CNTs and the high load-transfer efficiency of CNTs in the metal matrix. The fracture surface of the $\mathrm{CNT}(\mathrm{Ni} / \mathrm{Y})-\mathrm{Cu}$ composite under bending test indicates that almost all dimples, inferring ductile fracture mechanism of the composite, are evenly decorated by CNT tips, further confirming the high dispersion of CNTs. Moreover, all the CNTs that pull out are very short, meaning that some CNTs may be broken during the fracture and thus indicating that the load transfer from the matrix to the nanotube is sufficient to break the CNTs. Fig. 12b shows the fracture surface after a compression test. It can be observed that there are composite particles instead of single CNTs that pull out, also inferring the strong interfacial bonding strength between $\mathrm{CNTs}$ and $\mathrm{Cu}$. bridging $\mathrm{CNTs}$ between the pull-out particles and bulk composite can be observed (indicated by circle in Fig. 12b). As is known, there are three main load transfer mechanisms that control the full operation of the stress transfer, including micro-mechanical interlock, chemical bonding (interaction) and a weak van der Waals attractive force. Because $\mathrm{Cu}$ cannot react with untreated CNTs, chemical bonding between $\mathrm{CNTs}$ and $\mathrm{Cu}$ in our experiments is impossible. The weak van der Waals attractive force cannot transfer high loads. Thus, the possible main mechanism is micro-mechanical interlock. As observed by SEM, the nanotubes have physically contacted well with the $\mathrm{Cu}$ from the copper salt by mixing in a solution. Furthermore, the herringbone structure and uneven wall of CNTs also increase the micro-mechanical interlock strength.

\subsection{Other metal powders}

Apart from $\mathrm{Al}$ and Copper, other popular metal powders, such as $\mathrm{Ag}$ and $\mathrm{Mg}$, were also examined as catalyst support for CNT growth. For the Ni/Ag catalyst, the CVD processes were performed at temperatures among $500-700^{\circ} \mathrm{C}$. The weight of the catalyst before and after CVD was increased only a very little amount (<1wt.\%). TEM and SEM analysis showed that there was almost no carbon deposit observed in the product obtained at $500^{\circ} \mathrm{C}$, while, only a few amorphous carbon or graphite fragments was detected in the product obtained at $700^{\circ} \mathrm{C}$ and the diameter of most catalyst particles became micro-size level (Fig. 13), meaning that the activity and selectivity of the catalyst was impaired seriously even there was only a little diffusion of $\mathrm{Ag}$ into $\mathrm{Ni}$, apart from the aggregation of the catalyst.

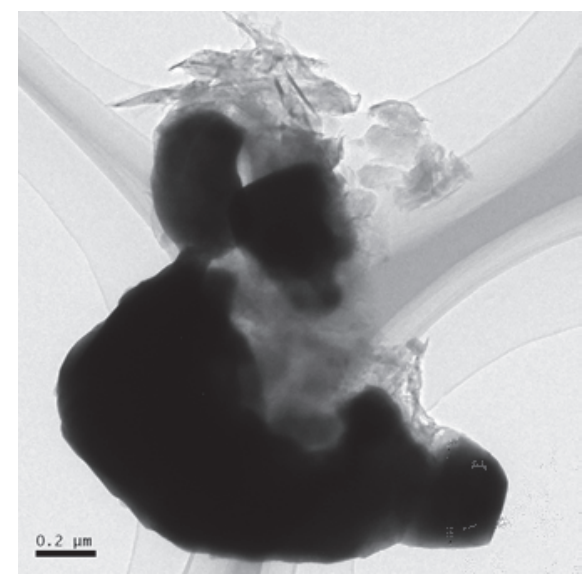

Fig. 13. TEM image of the products obtained by CVD using Ni/ Ag catalyst at $700^{\circ} \mathrm{C}$ 


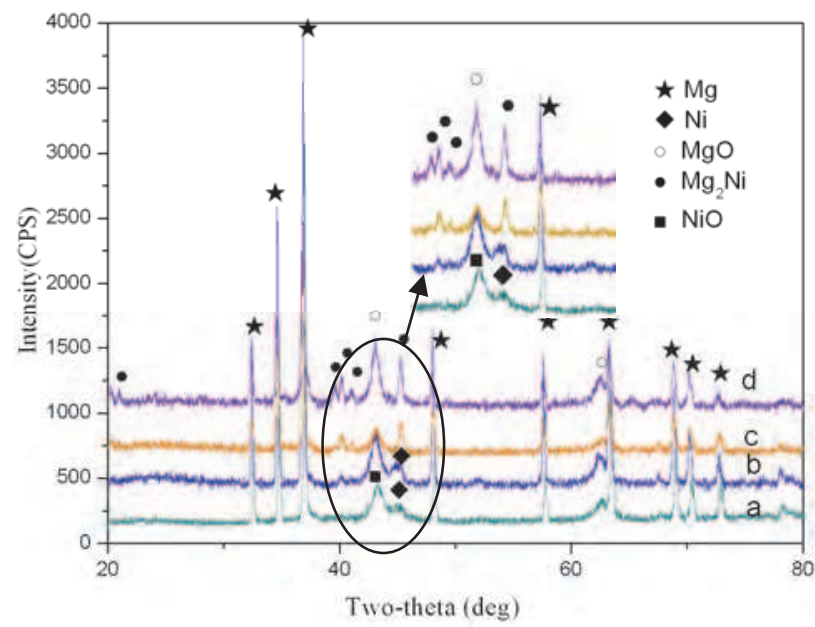

Fig. 14. XRD analysis of the $10 \% \mathrm{Ni} / \mathrm{Mg}$ catalyst precursor after calcination (a) and reaction products by $\mathrm{CVD}$ at $400^{\circ} \mathrm{C}(\mathrm{b}) ; 450^{\circ} \mathrm{C}$ (c) and $500^{\circ} \mathrm{C}(\mathrm{d})$
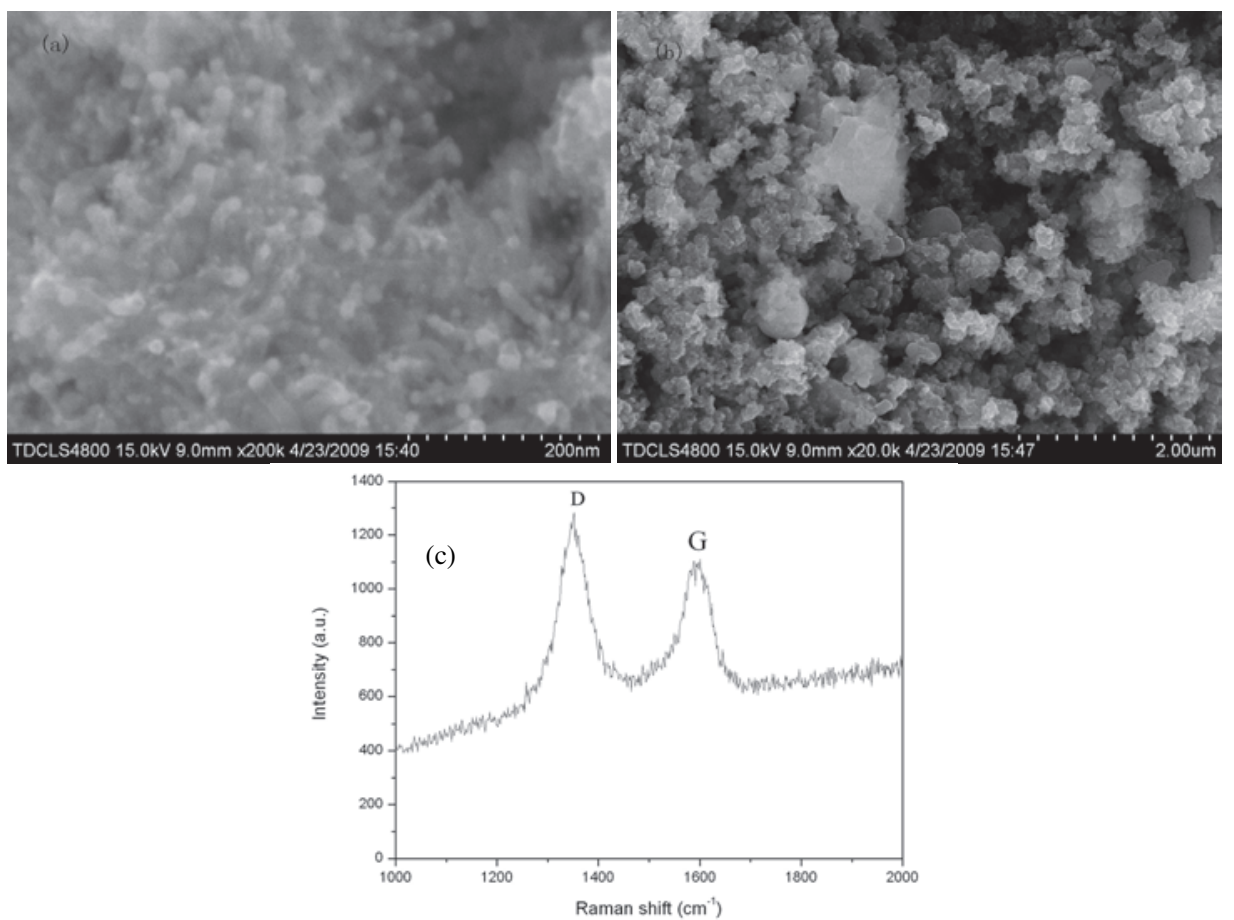

Fig. 15. SEM images and Raman spectra of the products obtained by CVD using Ni/Mg catalyst at $400^{\circ} \mathrm{C}(\mathrm{a}, \mathrm{c}) ; 450^{\circ} \mathrm{C}(\mathrm{b})$ 
Fig. 14 shows the XRD analysis of the products obtained by CVD using $\mathrm{Ni} / \mathrm{Mg}$ at various reaction temperatures. Both $\mathrm{Ni}$ and $\mathrm{MgO}$ peaks are detected in the product obtained at $400^{\circ} \mathrm{C}$. However, $\mathrm{MgO}$ can not resist the reactions between $\mathrm{Ni}$ and $\mathrm{Mg}$ at higher temperature, inferring that $\mathrm{MgO}$ is not compact and some $\mathrm{Ni}$ particles may be attached directly on the $\mathrm{Mg}$ surface. From Fig. $14 \mathrm{~b}$, it is observed that $\mathrm{Mg}_{2} \mathrm{Ni}$ begins to be formed when the temperature increases to $450^{\circ} \mathrm{C}$. SEM image and Raman spectrum show that short and thin CNTs are obtained at $400^{\circ} \mathrm{C}$ (Fig. 15a and c). When the reaction temperature is above $400^{\circ} \mathrm{C}$, there are almost no carbon deposits formed as shown in Fig. 15b, indicating that $\mathrm{Mg}_{2} \mathrm{Ni}$ can not catalyze the decomposition of $\mathrm{CH}_{4}$.

Based on the above analysis, it seems that the chemical reaction or diffusion between catalyst and substrate impairs the activity of the catalyst seriously. When the catalyst reacts with substrate, the catalyst will poison. The novel Ni/Y catalyst was also applied in $\mathrm{Ag}$ an $\mathrm{Mg}$ powders. Experimental results indicated that CNTs grown on Ag particles using $\mathrm{Ni} / \mathrm{Y}$ catalyst was similar with that on $\mathrm{Cu}$ particles. Ni/Y catalyst supported on $\mathrm{Mg}$, which presents a higher stability and catalytic property than $\mathrm{Ni}$ catalyst, was also successful to catalyze CNT growth directly on Mg particles. Those results infer that different metal supports have relative little effect on the activity of the catalyst if the reaction between catalyst and support is critically controlled, meaning that all metal powders are possible to be used as catalyst carriers for CNT growth by CVD. The works using these in situ CNT-metal composite powders to fabricate buck composites are in progress.

\section{Conclusion}

In summary, carbon nanotube integration with metal substrate by direct growth technique has been explored as a new approach for electronic device design and CNT-based composite fabrications. Many teams demonstrated solutions to the key challenge of growing highquality CNTs directly on various metal substrates. The performance of electronic devices by direct growth of CNTs, such as field emitters, supercapacitors, lithium ion batteries and ITMs, has been validated to be more excellent than that by external connection of CNTs. Direct growth of CNTs in metal powders can greatly improve the dispersion of CNTs in matrix and interfacial properties between CNTs and metal matrix, thus promoting the performance of the CNTs/metal composites. The next milestone will be the commercialization of this technology.

\section{Acknowledgment}

This work was sponsored by National Basic Research Program of China (2010CB934700), National Natural science Foundation of China (No.51071107 and No. 51001080) and the open project of The State Key Laboratory of Metal Matrix Composites (No. mmc-kf09-03).

\section{References}

Atthipalli, G.; Epur, R.; Kumta, R.; Allen, B.; Tang, Y.; Star, A.; Gray, J.; (2011), The effect of temperature on growth of carbon nanotubes on copper foil using a nickel thin film as catalyst, Thin Solid Films, in Press (doi:10.1016/j.tsf.2011.02.046) 
Baddour, C.; Fadlallah, F.; Nasuhoglu, D.; Mitra, R.; Vandsburger, L.; Meunier, J. (2008), A simple thermal CVD method for carbon nanotube synthesis on stainless steel 304 without the addition of an external catalyst, Carbon, 47, 313-347

Baddour, C.; Upham, D. \& Meumier, J. (2010). Direct and pepetitive growth cycles of caron nanotubes on stainless steel particles by chemical vapor deposition in a fluidized bed, Carbon, 48, 2652-2656.

Benito, S.; Lefferts L. (2010), The production of a homogeneous and well-attached layer of carbon nanofibers on metal foils, Carbon, 48, 2862-2872

Berber, S.; Kwon, Y. \& Tománek, D. (2000). Unusually high thermal conductivity of carbon nanotubes, Physics Review Letters, 84, 4613-4616.

Bult, J.; Sawyer, W.; Ajayan P.; Schadler L. (2009) Passivation oxide controlled selective carbon nanotube growth on metal substrates, Nanotechnology, 20, 085302(7pp)

Burt, D.; Whyte, W.; Weaver, J.; Glidle, A.; Edgeworth, J.; Macpherson, J.; Dobson, P.; (2009), Effects of metal underlayer grain size on carbon nanotube growth, Journal of Physics and chemistry: C, 2009, 113, 15133-151399

Cha, S.; Kim, T.; Arshad, S.; Mo, C. \& Hong, S. (2005), Extraordinary strengthening effect of carbon nanotubes in metal matrix nanocomposites processed by molecular-level mixing, Advanced Materials, 17, 1377-1381.

Cui, H.; Eres, G.; Howe, J.; Puretkzy, A.; Varela, M.; Geohegan, D.; Lowndes, D. (2003), Growth behavior of carbon nanotubes on multilayered metal catalyst film in chemical vapor deposition, Chemical Physics Letter, 374(3-4), 222-228.

$\mathrm{Du}, \mathrm{C}$; Pan, N. (2005) CVD growth of carbon nanotubes directly on nickel substrate, Materials Letters, 59, 1678-1682

Gan, B.; Ahn, J.; Zhang, Q.; Rusli; Yoon, S.F.; Yu, J. (2001) Y-junction carbon nanotubes grown by in situ evaporated copper catalyst, Chem. Phys. Lett. 333, 23-28

Gao, L. ; Peng, A. ; Wang, Z. ; Zhang, Hao. ; Shi, Z. ; Gu, Z. ; Cao, G. ; Ding, B. (2008), Growth of aligned carbon nanotube arrays on metallic substrate and its application to supercapacitors, Solid Communications, 146, 380-383

García, E.; Hart, A.; Wardle, B. \& Slocum, A. (2007). Fabrication and nanocompression testing of aligned carbon-nanotube-polymer nanocomposites, Advanced Materials, $19,2151-2156$.

García-Ce'spedes, J.; Thomasson, S.; Teo, K.; Kinloch, I.; Milne, W.; Pascual, E.; Bertran, E.; (2009), Efficient diffusion barrier layers for the catalytic growth of carbon nanotubes on copper substrates, Carbon, 47, 613-621.

Geffroy, P.; Chartier, T. \& Silvain, J. (2007). Preparation by tape casting and hot pressing of copper carbon composites films, Journal of the European Ceramic Society, 27, 291-299.

George, R.; Kashyap, K.; Rahul, R. \& Yamdagni, S. (2005). Strengthening in carbon nanotube/aluminium (CNT/Al) composites, Scripta Materialia, 53, 1159-1163.

Hiraoka, T. ; Yamada, T. ; Hata, K. ; Futaba, D. ; Kurachi, H. ; Uemura, S. ; Yumara M. ; Iijima, S. (2006), Synthesis of single- and double-walled carbon nanotube forests on conducting metal foils, Journal of American Chemical Society, 128, 13338-13339

Huang, M. ; Li, X.; Yi, H. ; Ma, N. \& Wang, H. (2005). Effect of in situ $\mathrm{TiB}_{2}$ particle reinforcement on the creep resistance of hypoeutectic Al-12Si alloy, Journal of Alloy and Compounds, 389, 275-280

Huang, Z. ; Yang, B. ; Cui, H. \& Zhang, J. (2003). Study on the fabrication of Al matrix composites strengthened by combined in-situ alumina particle and in-situ alloying elements, Materials Science and Engineering A, 351, 15-22

Iijima, S. (1991), Helical microtubules of graphitic carbon, Nature, 354 (6348), 56-58. 
Iijima, S. (2011). Science and industrial applications of nano-carbon materials such as fullerence, carbon nanotubes and graphenes, The 2011 WPI-AIMR Annual Workshop, Sendai, Japan.

Kang, Y. \& Chan, S. (2004). Tensile properties of nanometrix Al2O3 particulate-reinforced aluminum matrix composites, Materials Chemistry and Physics, 85, 438-443.

Kavian, R.; Vicenzo, A.; Bestetti, M.; (2011), Growth of carbon nanotubes on aluminium foil for supercapacitors electrodes, Journal of Materials Science, 46, 1487-1493.

Kim, B.; Chung H.; Chu, K.; Yoon, H.; Lee, C.; Kim, W.; (2010), Synthesis of verticallyaligned carbon nanotubes on stainless steel by water-assisted chemical vapor deposition and characterization of their electrochemical properties, Synthetic Metals, 160, 584-587.

Kim, K.; Cha, S.; Hong, S. \& Hong, S. (2006). Microstructures and tensile behavior of carbon nanotube reinforced $\mathrm{Cu}$ matrix nanocomposites, Materials Science and Engineering A, 430, 27-33.

Kim, P.; Shi, L.; Majumdar, A. \& McEuen, P. (2001). Thermal transport measurements of Individual multiwalled nanotubes, Physics Review Letters, 87, 215502 (4pp).

Kim, S.; Gangloff, L.; (2009), Growth of carbon nanotubes (CNTs) on metallic underlayers by diffusion plasma-enhanced chemical vapour deposition (DPECVD), Physica E, 41, 1763-1766

Kuzumaki, T.; Miyazawa, K.; Ichinose, H. \& Ito, K. (1998). Processing of carbon nanotube reinforced aluminum composite, Journal of materials Research, 13, 2445-2449.

Laha, T.; Agarwal, A.; Mckechnie, T. \& Seal, S. (2004). Synthesis and characterization of plasma spray formed carbon nanotube reinforced aluminum composite, Materials Science and Engineering A, 381, 249-258.

Lahiri, I.; Oh, S.; Hwang, J.; Cho, S.; Sun, Y.; Banerjee, R.; Choi, W.; (2010), High capacity and excellent stability of lithium ion battery anode using interface-controlled binderfree multiwall carbon nanotubes grown on copper, ACS Nano, 4, 3440-3446.

Lahiri, I.; Seelaboyina, R.; Hwang, J.; Banerjee, R.; Choi, W.; (2001), Enhanced field emission from multi-walled carbon nanotubes grown on pure copper substrate, Carbon, 48, 1531-1538

Lee, K.; Oh, D.; Choi, W.; Weissgärber, T. \& Kieback, B. (2007), Thermomechanical properties of AIN-Cu composite materials prepared by solid state processing, Journal of Alloy and Compounds, 434-435, 375-377.

Lepro' X. ; Lima, M. ; Baughman, R. (2010), Spinnable carbon nanotube forests grown on thin, flexible metallic substrates, Carbon, 48, 3621-3627

Li, C. ; Zhang, Y.; Mann, M. ; Hasko, D. ; Lei, W. ; Wang, B. ; Chu, D. ; Pribat, D. ; Amaratunga, G. ; Milne, W. ; (2010), High emission current density, vertically aligned carbon nanotube mesh, field emitter array, Applied Physics Letters, 97, 113107 (3pp)

Li, X. ; Zhang, X. ; Ci L. ; Shah R. ; Wolfe, C. ; Kar, S. ; Talapatra, S. ; Ajayan, P. ; (2008) Airassisted growth of ultra-long carbon nanotube bundles, Nanotechnology, 19, 455609(7pp)

Lin, W. ; Zhang, R.; Moon, K. ; Wong, C. ; (2010), Synthesis of high-quality vertically aligned carbon nanotubes on buck copper substrate for thermal management, IEEE Transactions on Advanced Packaging, 33, 370-376.

Lin, W. ; Zhang, R.; Moon, K. \& Wong, C. (2010). Molecular Phonon couplers at carbon nanotube/substrate interface to enhance interfacial thermal transport, Carbon, 48, 107-113. 
Liu, H.; Zhang, Y.; Arato, D.; Li, R.; Merel, P. \& Sun, X. (2008) Aligned multi-walled carbon nanotubes on different substrates by floating catalyst chemical vapor deposition: Critical effects of buffer layer, Surface Coating Technology, 202, 4114-4120

Mahanandia, P. ; Arya, V. ; Bhotla, P. ; Subramanyam, S. ; Schneider, J. ; Nanda, K. ; (2009), Excellent field emission from semialigned carbon nanofibers grown on cylindrical copper surface, Applied Physics Letters, 95, 083108 (3pp).

Martinez-latorre, L.; Ruiz-Cebollada, P.; Monzon, A.; Garcia-Bordeje, E. (2009), Preparation of stainless steel microreactors coated with carbon nanofiber layer: impact of hydrocarbon and temperature, Catalysis Today, 1475, 587-593

Masarapu C. ; Wei B. (2007) Direct growth of aligned multiwalled carbon nanotubes on treated stainless steel substrates, Langmuir, 23, 9046-9049

Mata, D.; Ferro, M.; Fernandes, A.J.S. ; Amaral, M. ;Oliveira, F.J. ; Costa, P. ; Silva, R. (2010) Wet-etched $\mathrm{Ni}$ foil as active catalysts towards carbon nanofiber growth, Carbon, 48, 1939-2854

Mauger, M. ; Binh, V. ; Levesque, A. ; Guillot, D. ; (2004), Freestanding vertically aligned arrays of individual carbon nanotubes on metallic substrates for field emission cathodes, Applied Physics Letters, 85, 385-387.

Moreno, M. \& Oliver, C. (2006). Compression creep of PM aluminum matrix composites reinforced with SiC short fibers, Materials Science and Engineering A, 418, 172-181.

Nessim, G. ; Seita, M. ; O’Brien, K. ; Hart, A . ; Bonaparte, R. ; Mitchell, R. ; Thompson, C. ; (2009), Low temperature synthesis of vertically aligned carbon nanotubes with electrical contact to metallic substrates enabled by thermal decomposition of the carbon feedstock, Nano Letter, 9, 3398-3405.

Nessim, G. ; Seita, M. ; O’Brien, K. ; Speakman, S. ; (2010), Dual formation of carpets of large carbon nanofibers and thin crystalline carbon nanotubes from the same catalystunderlayer system, Carbon, 48, 4519-4526.

Nessim, G. ; Acquaviva, D. ; Seita, M. ; O’Brien, K. ; Thompson, C. ; (2010), The critical role of the underlayer material and thickness in growing vertically aligned carbon nanotubes and nanofibers on metallic substrates by chemical vapor deposition, Advanced Functional materials, 20, 1306-1312.

Oye, M. ; Yim, S. ; Fu, A. ; Schwanfelder, K. ; Meyyapan, M. ; Nguyen, C. (2010), Surface smoothness effect for the direct growth of carbon nanotubes on bulk FeCrAl metal substrates, Journal of Nanoscience and Nanotechnology, 10, 4082-4088

Pal, S. ; Kar, S. ; Lastella S. ; Kumar, A. ; Vajtai, R. ; Talapatra, S. ; Borca-Tasciuc, T. ; Ajayan, P.; (2010), Importance of $\mathrm{Cr}_{2} \mathrm{O}_{3}$ layer for growth of carbon nanotubes on superalloys, Carbon, 48, 844-853

Peigney, A. ; Flahaut, E. ; Laurent, C. ; Chastel, F. \& Rousset, A. (2002). Aligned carbon nanotubes in ceramic-matrix nanocomposites prepared by high-temperature extrusion, Chemical Physics Letter, 352, 20-25

Qin, Y.; Zhang, Q.; Cui, Z.L.; (2004) Effect of synthesis method of nanocopper catalysts on the morphologies of carbon nanofibers prepared by catalytic decomposition of acetylene, J. Catal. 223, 389-394.

Reddy, N. ; Meunier J. ; Coulombe, S. (2006) Growth of carbon nanotubes directly on a nickel surface by thermal CVD, Matterials Letter, 60, 3761-3765

Schubert, T. ; Trindade, B. ; Weißgärber, T. \& Kieback, B. (2008). Interfacial design of Cubased composites prepared by powder metallurgy for heat sink applications, Materials Science and Engineering A, 475, 39-44.

Shyu, R. ; Weng, F. \& Ho, C. (2002). In situ reacted titanium nitride-reinforced aluminum alloy composite, Journal of Materials Processing Technology, 122, 301-304. 
Singh, M. ; Singh, P. Titus, E. ; Misra, D. ; LeNormand, F.; (2002), High density of multiwalled carbon nanotubes observed on nicke electroplated copper substrates by microwave plasma chemical vapor deposition, Chemical Physics Letters, 354, 331336.

Sung, W. ; Kim, W. ; Lee, H. ; Kim, Y. ; (2008), Field emission characteristics of carbon nanofibers grown on copper micro-tips at low temperature, Vacuum, 82, 551-555.

Talapatra, S. ; Kar, S. ; Pal, S. ; Vajtai, R. ; Ci, L. ; Victor, P. ; Shaijumon, M. ; Kaur, S. ; Nalamasu, O. ; Ajayan. (2006), Direct growth of aligned carbon nanotubes on bulk metals, Nature Nanotechnology, 1, 112-116

Tang, F. ; Anderson, I. \& Biner, S. (2003). Microstructures and mechanical properties of pure $\mathrm{Al}$ matrix composites reinforced by Al-Cu-Fe alloy particles, Materials Science and Engineering A, 363, 20-29.

Venegoni, D. ; Serp, P. ; Feurer, R. ; Kihn, Y. ; Vahlas, C. \& Kalck, P. (2002). Parametric study for growth of carbon nanotubes by catalystic chemical vapor deposition in a fluidized bed reactor, Carbon, 40, 1799-1807.

Wang, H. ; Feng, J. ; Hu, X. \& Ng, K. (2007). Synthesis of aligned carbon nanotubes on double-sided metallic substrate by chemical vapor deposition, Journal of Physics and Chemistry: C, 111, 12617-12624.

Wang, B. ; Liu, X. ; Liu, H. ; Wu, D. ; Wang, H. ; Jiang, J. ; Wang, X. ; Hu, P. ; Liu, Y. ; Zhu, D. ; (2003), Cotrollable preparation of patterns of aligned carbon nanotubes on metals and metal-coated silicon substrates, Journal of Materials Chemistry, 13, 11241126.

Wu, H. ; Wang, Z. ; Zheng, Q. \& Zhou, J. (2006) The review and prospect of copper-matrix composites for electronic packaging, China Molybdenum Industry, 03, 30-32

Yi, W. \& Yang, Q. (2010), CVD growth and field electron emission of aligned carbon nanotubes on oxidized inconel plates without addition of catalyst, Diamond $\mathcal{E}$ Related Materials, 19, 870-874.

Yin, X. ; Wang, Q. ; Lou, C. ; Zhang, X. \& Lei, W. (2008). Growth of multi-walled CNTs emitters on an oxygen-free copper substrate by chemical-vapor deposition, Applied surface Science, 254, 6633-6636

Zambon, A. ; Badan, B. \& Maddalena, A. (2004). Production, microstructural and mechanical characterizaition of spray formed Al-6 wt.\% Fe alloy and pre-mixed Al-6 wt.\% $\mathrm{Fe} / \mathrm{SiC}_{\mathrm{p}}$ composite, Materials Science and Engineering A, 375-377, 645-650.

Zhang, L., Tan, Y. \& Resasco, D. (2006). Controlling the growth of vertically oriented singlewalled carbon nanotubes by varying the density of Co-Mo catalyst particles, Chemical Physics Letter, 422(1-3), 198-203.

Zhang, Z.; He, P.; Sun, Z.; Feng, T.; Chen, Y.; Li, H. \& Tay, B. (2010) Growth and field emission property of coiled carbon nanostructure using copper as catalyst, Applied Surface Science, 256, 4417-4422

Zhu, S. \& Lizuka, T. (2003). Fabrication and mechanical behaviou of Al matrix composites reinforced with porous ceramic of in situ grown whisker framework, Materials Science and Engineering A, 354, 306-314. 


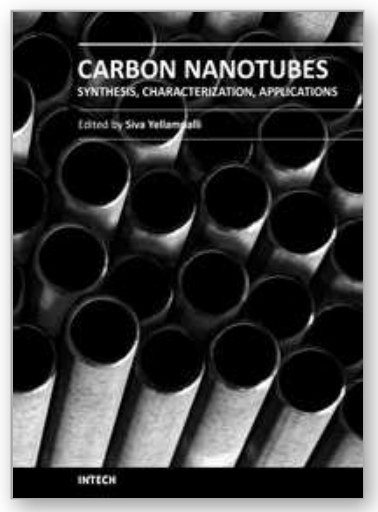

\section{Carbon Nanotubes - Synthesis, Characterization, Applications}

Edited by Dr. Siva Yellampalli

ISBN 978-953-307-497-9

Hard cover, 514 pages

Publisher InTech

Published online 20, July, 2011

Published in print edition July, 2011

Carbon nanotubes are one of the most intriguing new materials with extraordinary properties being discovered in the last decade. The unique structure of carbon nanotubes provides nanotubes with extraordinary mechanical and electrical properties. The outstanding properties that these materials possess have opened new interesting researches areas in nanoscience and nanotechnology. Although nanotubes are very promising in a wide variety of fields, application of individual nanotubes for large scale production has been limited. The main roadblocks, which hinder its use, are limited understanding of its synthesis and electrical properties which lead to difficulty in structure control, existence of impurities, and poor processability. This book makes an attempt to provide indepth study and analysis of various synthesis methods, processing techniques and characterization of carbon nanotubes that will lead to the increased applications of carbon nanotubes.

\section{How to reference}

In order to correctly reference this scholarly work, feel free to copy and paste the following:

Naiqin Zhao and Jianli Kang (2011). Direct Growth of Carbon Nanotubes on Metal Supports by Chemical Vapor Deposition, Carbon Nanotubes - Synthesis, Characterization, Applications, Dr. Siva Yellampalli (Ed.), ISBN: 978-953-307-497-9, InTech, Available from: http://www.intechopen.com/books/carbon-nanotubessynthesis-characterization-applications/direct-growth-of-carbon-nanotubes-on-metal-supports-by-chemicalvapor-deposition

\section{INTECH}

open science | open minds

\section{InTech Europe}

University Campus STeP Ri

Slavka Krautzeka 83/A

51000 Rijeka, Croatia

Phone: +385 (51) 770447

Fax: +385 (51) 686166

www.intechopen.com

\section{InTech China}

Unit 405, Office Block, Hotel Equatorial Shanghai

No.65, Yan An Road (West), Shanghai, 200040, China

中国上海市延安西路65号上海国际贵都大饭店办公楼 405 单元

Phone: +86-21-62489820

Fax: $+86-21-62489821$ 
(C) 2011 The Author(s). Licensee IntechOpen. This chapter is distributed under the terms of the Creative Commons Attribution-NonCommercialShareAlike-3.0 License, which permits use, distribution and reproduction for non-commercial purposes, provided the original is properly cited and derivative works building on this content are distributed under the same license. 